Research paper

\title{
Recovery from exhaustive swimming and its effect on fillet quality in haddock (Melanogrammus aeglefinus)
}

\author{
Anders Karlsson-Drangsholt ${ }^{\mathrm{a}, 1}$, Ragnhild Aven Svalheim ${ }^{\mathrm{b}}$, Øyvind Aas-Hansen ${ }^{\mathrm{b}, 2}$, Stein-Harris Olsen ${ }^{\mathrm{b}}$, \\ Kjell Midling ${ }^{\mathrm{b}}$, Michael Breen ${ }^{\mathrm{c}}$, Endre Grimsb $\varnothing^{\mathrm{c}}$, Helge Kreutzer Johnsen ${ }^{\mathrm{a}}$, \\ ${ }^{a}$ University of Troms $\phi$, Faculty of Biosciences, Fisheries and Economics, Norwegian College of Fishery Science, Muninbakken 21, N-9037, Troms $\phi$, Norway \\ ${ }^{\mathrm{b}}$ Nofima - The Food Research Institute, Muninbakken 9-13, 9291, Troms $\phi$, Norway \\ ${ }^{\mathrm{c}}$ Institute of Marine Research, Nordnesgaten 50, 5005, Bergen, Norway
}

\section{A R T I CLE INFO}

Handled by George A. Rose

\section{Keywords:}

Haddock

Melanogrammus aeglefinus

Exhaustive swimming

Swim tunnel

Fillet quality

\begin{abstract}
A B S T R A C T
Wild haddock (Melanogrammus aeglefinus) of commercial size $(0.8-2.49 \mathrm{~kg}, 45-60 \mathrm{~cm}$ ) were swum to exhaustion in a large swim tunnel and then allowed to recuperate for 0,3 or $6 \mathrm{~h}$, to investigate the effects of exhaustive swimming on blood glucose, blood lactate and post mortem development of fillet quality. There was a positive linear relationship between critical (aerobic) swimming speed $\left(\mathrm{U}_{\text {crit }}\right)$ and body length (BL). The average $\mathrm{U}_{\text {crit }}$ was $1.25 \pm 0.29$ (SD) $\mathrm{BL} \mathrm{s}^{-1}$, which is close to that reported by others for haddock. Swimming to exhaustion resulted in reduced time to reach maximum muscle stiffness of the fillet (no recuperation vs unswum control), but the effect was remedied by recuperation for $3 \mathrm{~h}$ or more. Blood glucose and blood lactate increased during exercise and remained elevated throughout the entire 6-h resting period, indicating that complete recovery of these parameters may take more than $6 \mathrm{~h}$. There was no significant effect of exhaustive swimming on muscle $\mathrm{pH}$ or colouration of the fillet. Taken together, the data suggest that swimming to exhaustion may have moderate and reversible negative effects on fillet quality in haddock. The effects observed in the present study are consistent with a recent study on exhaustive swimming in Atlantic cod, but less severe than that reported for haddock caught by trawl. This suggests that other factors (e.g. crowding/packing in the codend, barotrauma or suffocation) are contributing to the deterioration of fillet quality seen frequently in haddock caught by trawl.
\end{abstract}

\section{Introduction}

Trawl fishing accounted for $55 \%$ of the average yearly landings of haddock (Melanogrammus aeglefinus) in Norway from 2005 to 2013 (Norwegian fish landing statistics, 2014). Trawling of both haddock (Digre et al., 2017) and Atlantic cod (Gadus morhua) (Olsen et al., 2013) has been shown to induce poorer fillet quality than longlining (Roth and Rotabakk, 2012), depending on duration and size of the haul (Margeirsson et al., 2007; Olsen et al., 2013). Pre-slaughter fatigue is a major cause of reduced post mortem quality and shelf-life of fish (Cole et al., 2003) and line-caught fish is generally considered to be of better quality than fish caught by active gears such as trawl and Danish seine.
For instance, cod and haddock caught by line may give a price premium of 18 and 10\%, respectively, in the UK (Sogn-Grundvåg et al., 2013).

Discolouration of the fillet and low muscle $\mathrm{pH}$ are two important causes of reduced quality in white fish. Residual blood in the white muscle may give the fillet a reddish or dark appearance, which is an aesthetic problem and a quality defect as the consumer expects white fish to be white. A low muscle $\mathrm{pH}$, on the other hand, affects the quality of the fillet indirectly by shortening the time to full muscle stiffness during rigor mortis. Before filleting, the fish has to be straightened (unfolded), which could cause muscle tears followed by gaping and dryness of the fillet if this occurs during full muscle rigor (and not during pre-rigor) (Borderías and Sánchez-Alonso, 2011; Olsson et al.,

\footnotetext{
* Corresponding author.

Email address: helge.johnsen@uit.no (H.K. Johnsen)

1 Present affiliation: Bellona, Vulkan 11, 0178, Oslo, Norway.

2 Present affiliation: The Norwegian Radiation Protection Authority, Section High North, The Fram Centre, Tromsø, Norway.
} 
2007). Discolouration of the fillet and muscle gaping may both lead to downgrading of the fish and financial loss for the producer (Michie, 2001; Robb and Whittington, 2004).

The exact cause of the poor fillet quality frequently seen in trawled fish is unknown, but studies on farmed fish have shown that different types of handling stress prior to slaughter may increase the amount of residual blood in the fillet (Skjervold et al., 1999; Robb et al., 2003; Roth et al., 2005; Olsen et al., 2006; Olsen et al., 2008; Roth et al., 2009). Thus, it is reasonable to assume that the various events of the trawl fishing operation the fish have to go through, such as swimming to exhaustion, crowding in the codend, decompression and subsequent barotrauma when lifting the trawl, may represent potential stressors that could contribute to deterioration of fillet quality (Svalheim et al., 2017). To prevent the poor fillet quality observed in trawled fish, it is therefore important to identify which stage(s) are most detrimental to quality and where efforts should be directed to improve the process.

The normal towing speed of a bottom trawl (1-2 $\left.\mathrm{m} \mathrm{s}^{-1}\right)$ exceeds the maximum sustainable swimming speed of haddock $\left(\leq 0.65 \mathrm{~m} \mathrm{~s}^{-1}\right.$; Breen et al., 2004), which have been reported to swim at the same speed and direction as the trawl with a 'kick and glide' style until they stop swimming (Main and Sangster, 1981). This suggests that most haddock will be exhausted once they enter the codend. The primary cause of exhaustion during swimming is considered to be due to insufficient supply of oxygen to fuel the aerobic red swimming muscles (Reidy et al., 2000), but swimming may also reduce white (anaerobic) muscle energy stores (Lurman et al., 2007). The white muscle mass makes up the largest part of the fillet in haddock and the $\mathrm{pH}$ of the white muscle at slaughter is important for the fillet quality later on (Borderías and Sánchez-Alonso, 2011).

During normal recovery from exhaustion (capture in trawl), blood lactate of haddock has been shown to return to pre-exercise levels after $12 \mathrm{~h}$ (Beamish, 1966). The recovery of white muscle metabolic status (i.e. white muscle $\mathrm{pH}$ and lactate) may be expected to follow a similar pattern, as suggested by data from other species (Beamish, 1968; Wood, 1991). The white muscle in rainbow trout (Oncorhynchus mykiss) receives up to $80 \%$ of the cardiac output during recovery from exhaustive swimming (Neumann et al., 1983). A similar response may take place in gadoids and could explain, at least in part, the increase in fillet redness observed in haddock (Digre et al., 2017) and cod (Olsen et al., 2013) caught by trawl. However, it remains uncertain if a full recovery of the white muscle metabolic status is necessary to return fillet quality parameters to pre-exercise levels, as fillet quality in Atlantic cod caught by trawl may improve substantially after only $6 \mathrm{~h}$ of live storage in tanks (Olsen et al., 2013). A recent study on Atlantic cod further suggests that white muscle $\mathrm{pH}$ is restored more quickly than the stress induced increase in blood glucose after exhaustive swimming (Svalheim et al., 2017). In the current study, we aim to investigate if swimming to exhaustion may contribute to the poor fillet quality reported in haddock caught by trawl, and if post exercise recuperation for 3 or $6 \mathrm{~h}$ can normalize fillet quality. We have addressed these questions by measurements of muscle $\mathrm{pH}$, time to full muscle stiffness (rigor), muscle redness, as well as blood glucose and lactate concentrations in a group of haddock swum to exhaustion in a novel experimental swim tunnel.

\section{Materials and methods}

\subsection{Fish and pre-swimming experimental conditions}

Wild haddock were caught by a Norwegian purse seine vessel (Korsnesfisk) in Sandfjorden (Sørøya, Norway) in early November 2012 at $30-40 \mathrm{~m}$ depths. The haddock $(\mathrm{n}=50)$ were collected randomly from the purse seine, placed in an on-board $800 \mathrm{~L}$ container supplied with fresh seawater $\left(50 \mathrm{~L} \mathrm{~min}^{-1}\right)$, and subsequently transported to the
Aquaculture Research Station in Troms $\varnothing$, Norway, where the experiment took place. The fish were kept indoors under natural photoperiod (transparent roof, $69^{\circ} \mathrm{N}$ ) and water temperature (maximum $8.5^{\circ} \mathrm{C}$ in October, minimum $2.6^{\circ} \mathrm{C}$ in mid-March) in a $2 \mathrm{~m}$ diameter, $4 \mathrm{~m}^{3}$ volume circular tank for 6 months before the experiment commenced in late April 2013 (water temperature $3.5^{\circ} \mathrm{C}$ ). The water supply was taken at a depth of $50 \mathrm{~m}$ and it is assumed that the temperature of the water was close to that experienced by wild haddock in their natural habitat. The fish were inspected twice daily, and moribund fish (suffering from skin damage or barotrauma after catch) were immediately removed and euthanized by a blow to the head. The fish were fed daily to satiation, using a mixture of capelin (Mallotus villosus) and commercial feed (Skretting Amber $5 \mathrm{~mm}$, Skretting ASA, Norway). Feed was removed $48 \mathrm{~h}$ prior to sampling of controls and transfer of fish into the swim tunnel (see section 2.2). A total of 26 fish (13 males and 13 females) with an average body weight (BW) of $1.57 \pm 0.46$ (mean $\pm \mathrm{SD}$ ) $\mathrm{kg}$ (range 0.80-2.49), an average body length (BL) of $51.9 \pm 3.7$ (mean \pm SD) $\mathrm{cm}$ (range 45.0-59.7), an average condition factor of $1.10 \pm 0.17$ (mean \pm SD) (range 0.60-1.34), an average gonadosomatic index $(\mathrm{GSI})$ of $0.05 \pm 0.06)($ mean $\pm \mathrm{SD}$ ) (range 0.01-0.18) and an average hepatosomatic index (HSI) of $0.12 \pm 0.04$ (mean \pm SD) (range 0.03-0.27) were used in the experiment (Table 1), divided between a control group of non-exercised fish $(n=6)$ and the experimental group subjected to swimming in the tunnel $(n=20)$. Prior to the start of the experiment, the control fish were netted randomly from the tank, euthanized and sampled according to the same procedure as the other fish (see Section 2.4). The remaining fish $(\mathrm{n}=20)$ were then transferred to the swim tunnel and allowed to acclimate for $24 \mathrm{~h}$ at a low water speed of $0.1 \mathrm{~m} \mathrm{~s}^{-1}\left(\sim 0.2 \mathrm{BL} \mathrm{s}^{-1}\right)$.

\subsection{Swim tunnel}

The swim tunnel was custom made to provide an experimental setup for swimming trials with groups of large fish. It consisted of a

\section{Table 1}

Median values and 95\% confidence intervals of condition factor (CF), hepatosomatic index (HSI), gonadosomatic index (GSI), muscle $\mathrm{pH}$ measured immediately after death $\left(\mathrm{pH}_{\text {start }}\right)$, $\mathrm{pH}$ measured at the end of the $60-80 \mathrm{~h}$ storage period $\left(\mathrm{pH}_{\text {end }}\right)$, fillet colouration (Hunter's Whiteness Index) and maximum muscle stiffness in controls (Rested control) and recovery groups ( $0 \mathrm{~h}, 3 \mathrm{~h}$ and $6 \mathrm{~h})$.

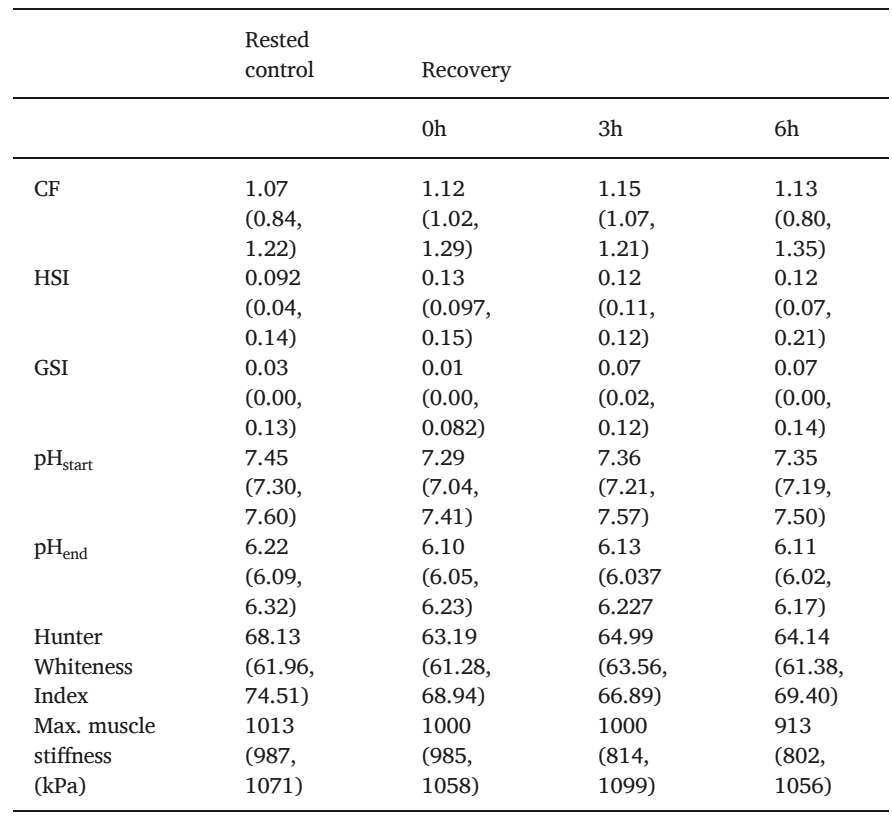


collection of $0.8 \mathrm{~m}$ inner diameter black, high density polyethylene pipes (BorsafeTM HE3490-LS, Borealis AG, Vienna, Austria), a 3-blade propeller with an integrated $5.5 \mathrm{~kW}$ electrical motor (Flygt PP4650.410 with $11^{\circ}$ blade angles, Xylem Water Solutions, Charlotte, NC, USA) secured in a $0.8 \mathrm{~m}$ inner diameter aluminum tube housing and a $1400 \mathrm{~L}$ octagonal aluminum swim chamber $(2.8 \mathrm{~m}$ in length and $0.8 \mathrm{~m}$ in inner height and inner width; Fig. 1). The swim chamber was equipped with an acrylic glass top hatch for loading of fish and a transparent side window for underwater camera observation of the fish. The tunnel was submerged in an $11 \mathrm{~m}$ inner diameter circular tank supplied with filtered seawater of natural temperature. To minimize turbulence, a flow director made from square pipes $(5 \times 5 \mathrm{~cm})$ of $1 \mathrm{~m}$ length, was placed in front of the swim chamber. Grids, preventing fish from escaping the swim chamber, were made from plastic coated stainless steel strands (SS grid) placed in the front and rear ends of the chamber. The lower half of the rear grid slanted, so that its lowest point protruded ca $0.4 \mathrm{~m}$ into the swim chamber. Thus, it directed exhausted fish to the upper half of the rear grid, which was attached to the lower half with hinges and could be opened to remove exhausted fish individually. A retaining box made from SS was placed behind the chamber to prevent fish from escaping further into the tank when the rear grid was opened (Fig. 1).

Water velocity in the tunnel was controlled by changing the electrical motor revolutions per minute (RPM) and thereby the propeller speed. RPM was controlled by sending a 4-20 mA signal on the motors frequency converters analog input (11 bit resolution). The 4-20 mA signal was generated by a NI 9265 USB measurement bundle from National Instruments, Austin, TX, USA (NI) controlled by a specially developed software application designed in LabVIEW (NI). The software application was designed as a feed forward control, where the algorithm gave an analog output 4-20 mA signal by using a transfer function calculated from the swim tunnel's flow calibration results. It was then possible to set the swim tunnel's flow velocity from the interface of the control system.

\subsection{Experimental protocol and conditions}

A method based on Brett (1964) was used to calculate critical swimming speed $\left(\mathrm{U}_{\text {crit }}\right)$ for all individuals:

$U_{\text {crit }}=V_{n-1}+\left(\frac{t_{n}}{t_{i}}\right) \cdot V_{i}$

where:

$\mathrm{V}_{\mathrm{n}-1}=$ the highest water speed $\left(\mathrm{m} \mathrm{s}^{-1}\right)$ the fish could successfully swim at for $30 \mathrm{~min}$

$\mathrm{V}_{\mathrm{i}}=$ the water speed increment $\left(\mathrm{m} \mathrm{s}^{-1}\right)$

$t_{n}=$ the time in minutes the fish swam at the speed it became exhausted

$\mathrm{t}_{\mathrm{i}}=$ the duration in minutes of each water speed step.

After $24 \mathrm{~h}$ acclimation in the swim tunnel at $0.1 \mathrm{~m} \mathrm{~s}^{-1}$, the water speed was increased in steps of $0.00133 \mathrm{~m} \mathrm{~s}^{-1}$ over $5 \mathrm{~min}$, until a speed of $0.5 \mathrm{~m} \mathrm{~s}^{-1}$ was reached. This speed was maintained for $30 \mathrm{~min}$, and after that the water speed was increased with $0.05 \mathrm{~m} \mathrm{~s}^{-1}$ increments every 30 min until all fish stopped swimming. Exhaustion was defined as the speed at which a fish would no longer swim, despite encouraging the fish to move away from the grid by pinching (with fingers) the tail gently for $10 \mathrm{~s}$. Fish that did not respond to pinching was either transferred to separate floating cages (SS grid; $60 \times 30 \times 20 \mathrm{~cm}$, length $\mathrm{x}$ width $\mathrm{x}$ depth) for recovery ( 3 or $6 \mathrm{~h}$ ) or euthanized immediately and sampled. Water temperature during acclimation, swimming and recovery ranged from 3.5 to $4.5{ }^{\circ} \mathrm{C}$ and oxygen saturation was always between 97 and 100\%.

\subsection{Sampling and on-site fillet quality measurements}

Blood was sampled from the caudal vessels, using $6 \mathrm{~mL}$ heparinized vacuum tubes (Vacutainer ${ }^{\circledR}$ ) and $40 \times 0.9 \mathrm{~mm}$ needles (BD Diagnostics, Franklin Lakes, NJ). The blood samples were analyzed immediately for lactate (Lactate Scout, EKF Diagnostics, Cardiff, UK) and glucose (FreeStyle Lite, Abbott Diabetes Care Inc., California, USA). To measure

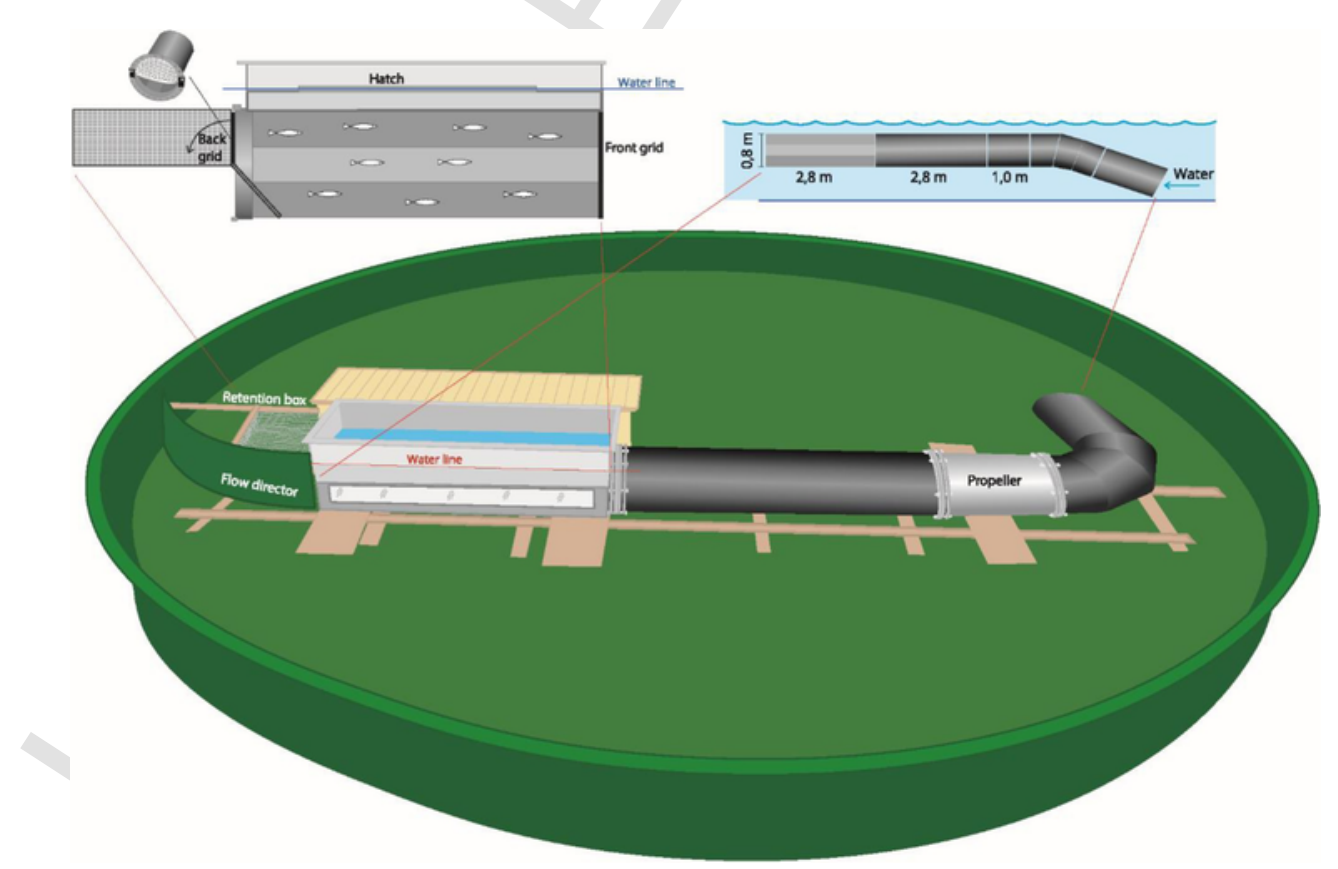

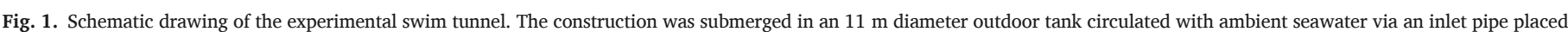

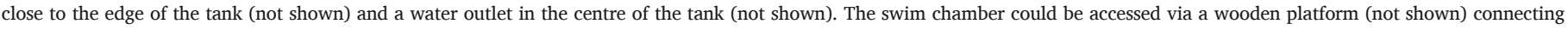
the tunnel system with the area outside the tank. 
initial $\mathrm{pH}$ in the white muscle $\left(\mathrm{pH}_{\text {start }}\right.$ ), a small incision (ca $1 \mathrm{~cm}$ ) was made with a scalpel approximately $3 \mathrm{~cm}$ ventral to the posterior attachment of the first dorsal fin (Fig. 2A). The pH was measured with a hand held WTW330/set-1 pH-meter (Wissenscaftliche-TechnischeWerkstätten, Weilheim, Germany) equipped with a Hamilton double pore glass electrode (Hamilton Bonaduz AG, Bonaduz, Switzerland). The instrument was calibrated frequently using $\mathrm{pH} 4.01$ and pH 7.00 buffers, and the electrode was cleaned regularly to obtain consistent results. The fish was then bled out by cutting the Bulbus arteriosus and Vena cardinalis communis while left in cold $\left(4^{\circ} \mathrm{C}\right)$, running seawater for $30 \mathrm{~min}$. The fish were then weighed, length measured, gutted and sex determined before the organs were weighed. Each fish was then placed in standard plastic fish boxes with the belly down, covered with ice and stored for $60 \mathrm{~h}$ or more to track development of muscle stiffness (as an indicator of rigor mortis) measured by use of a hand held Effegi penetrometer (FT 02 Penetrometer, QA Supplies LLC, Virginia, USA), according to Berg et al. (1997). Briefly, the maximum force $(\mathrm{kPa})$ required to push a $8 \mathrm{~mm}$ diameter stainless steel plunger $5 \mathrm{~mm}$ into the fillet was recorded. Measurements were made repeatedly on 4 different locations (spaced approximately $50 \mathrm{~mm}$ apart) along the loin (Fig. 2B). Muscle stiffness was recorded approximately every $4 \mathrm{~h}$ the first $12 \mathrm{~h}$, then approximately every $8 \mathrm{~h}$ for the remainder of the storage period, until the peak in muscle stiffness was passed. After the recording of muscle stiffness was completed, a final measurement of muscle $\mathrm{pH}\left(\mathrm{pH}_{\text {end }}\right)$ was obtained at the same place as the initial $\mathrm{pH}_{\text {start }}$ Muscle samples and measurements of $\mathrm{pH}$ were taken from the left loin, whereas measurements of muscle stiffness were obtained repeatedly on the same surface area on the right loin. The fish was then filleted and colouration (given as fillet whiteness; Hunter's Whiteness Index) was recorded on three locations along the right loin (approximately $20 \mathrm{~mm}$ apart) in approximately the same area where measurements of muscle stiffness were obtained (see Fig. 2B), using a hand-held Minolta CR-200 Chroma Meter colorimeter (Minolta, Japan).
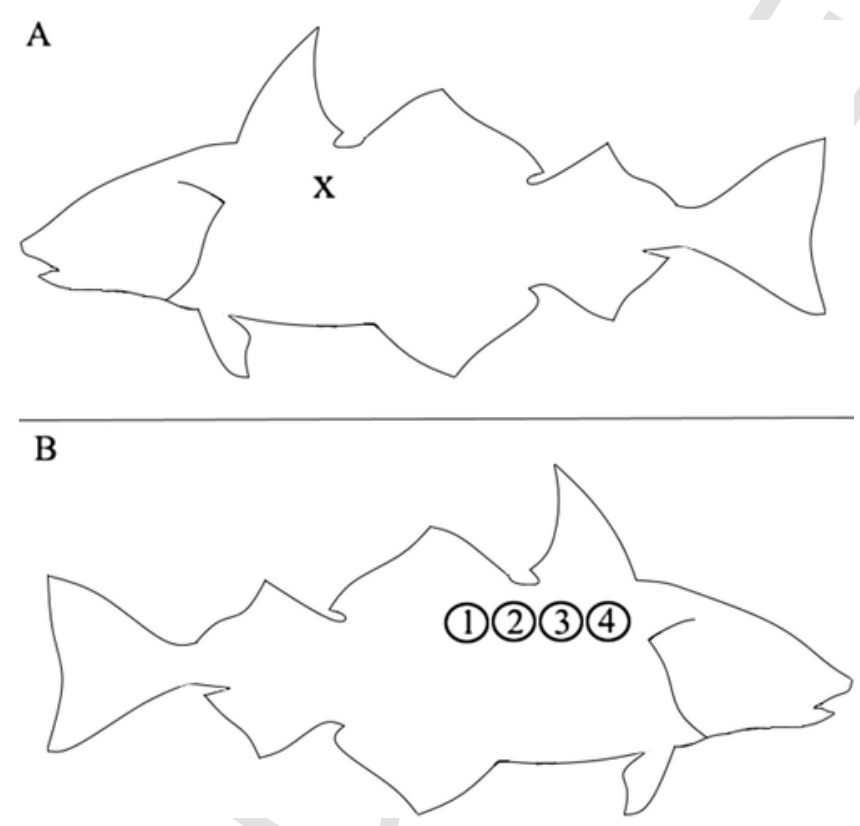

Fig. 2. Schematic diagram of the locations on the fish where measurements of muscle pH (A) and muscle stiffness (B) were made. Fillet colouration (Hunter's Whiteness Index) was recorded on the internal side of the right loin (after the fish was filleted) in the same area as measurements of muscle stiffness where obtained (B).

\subsection{Statistical analyses and data management}

The data were analysed with the statistical software R, version 3.2.0 ( $\mathrm{R}$ core team, 2015). The relationships between different quality metrics [i.e. Hunter Whiteness Index, muscle $\mathrm{pH}_{\text {start }}$ muscle $\mathrm{pH}_{\text {end }}$, maximum rigor $(\mathrm{kPa})$ and time to maximum rigor (hours)] and corresponding potential explanatory variables [i.e. recovery time (as factor; groups: control, 0, $3 \& 6 \mathrm{~h}$ ), sex (as factor), fish length $(\mathrm{cm}), \mathrm{U}_{\text {crit }}\left(\mathrm{m} \mathrm{s}^{-1}\right)$, blood glucose $\left(\mathrm{mM} \mathrm{L}^{-1}\right)$, blood lactate $\left(\mathrm{mM} \mathrm{L}^{-1}\right)$, hepatosomatic index (HSI), gonadosomatic index (GSI) and Fulton's condition factor $\left.\left(100 \mathrm{~g} \mathrm{~cm}^{-3}\right)\right]$ were investigated using Generalised Linear Modelling (GLM) (McCullagh and Nelder, 1999; Buckley, 2015). Before proceeding with the GLM analysis, the data were checked and prepared for modelling following the procedures described by Zuur et al. (2009). Each GLM was constructed from a linear predictor $\left(\eta_{i}\right)$, an error distribution (e.g. Normal/Gaussian or Gamma) and a link function $\left(\mathrm{g}_{\mathrm{i}}\right)$ (e.g. identity, inverse or $\log$ ).

The linear predictor $\left(\eta_{\mathrm{i}}\right)$ is the systematic part of the model which describes how covariates and factors ultimately contribute to the expected value (prediction) for an observation.

$\eta_{i}=b_{0}+b_{1} \cdot x_{1 i}+\ldots+b_{h} \cdot x_{h i}$

The most parsimonious GLM was identified for each response variable, from all relevant explanatory variables, using a backwards selection procedure. However, because of the small sample size $(n=26)$, it was necessary to conduct the selection process with caution to avoid over-parameterisation of the initial full and any subsequent models. Thus, first, each response variable was modelled individually with each relevant explanatory variable, with recovery group or sex as co-variates where relevant. Then the initial full model was limited to only biologically relevant and significant $(p<0.1)$ explanatory variables. Subsequent models were constructed by sequentially removing the variables that contributed least to the model deviance, until only significant variables $(p \leq 0.05)$ remained in the final model (as determined by log-likelihood ratio test and AIC) (Akaike, 1974; Burnham and Anderson, 2004). Finally, the validity of each model selection was further tested by removing any highly influential data points to assess their importance for the model coefficients and inferences.

The error distribution allows the model to estimate the random error associated with each predicted value $\left(y ?_{i}\right)$ based upon a known distribution.

$$
\begin{array}{ll}
\text { Gaussian(Normal) } & \bar{y}_{i} \sim N\left(\mu_{i}, \sigma_{i}^{2}\right) \\
\mathrm{E}\left(Y_{i}\right)=\mu_{i} & \text { and } \quad \operatorname{var}\left(Y_{i}\right)=\sigma_{i}^{2} \\
\text { Gamma } & \bar{y}_{i} \sim \Gamma\left(\alpha_{i}, \beta_{i}\right) \\
\mathrm{E}\left(Y_{i}\right)=\alpha_{i} \cdot \beta_{i} & \text { and } \quad \operatorname{var}\left(Y_{i}\right)=\alpha_{i} \cdot \beta_{i}^{2}
\end{array}
$$

Most of the response variables had positive values (i.e. not less than zero). Such data are best modelled using a Gamma distribution, which accounts for the skewed distribution of the model errors and prevents nonsensical negative predications. A further property of the Gamma distribution is that it assumes a constant ratio between the mean and variance (i.e. it will increase in proportion with the mean), which can help address heterogeneity in the data. Hunter's Whiteness Index, $\mathrm{pH}_{\text {start }}$ and $\mathrm{pH}_{\text {end }}$ were all initially modelled using Gaussian (Normal) error distributions. However, due to skewness in the data, Hunter's Whiteness Index and $\mathrm{pH}_{\text {start }}$ had better fits using Gamma error distributions.

The link function $(\mathrm{g})$ relates the expected (typically mean) value $(\mu)$ of the observed values $(y)$ to its linear predictor $(\eta)$. 


$$
\begin{aligned}
& \text { identitylink } \\
& \text { : } \eta_{i} \\
& =g\left(\mu_{i}\right) \\
& =\mu_{i} \\
& \rightarrow \mu_{i} \\
& =g\left(\eta_{i}\right)^{-1} \\
& =\eta_{i}
\end{aligned}
$$

identitylink : $\eta_{i}=g\left(\mu_{i}\right)=\mu_{i} \rightarrow \mu_{i}=g\left(\eta_{i}\right)^{-1}=\eta_{i}$ inverselink: $\eta_{i}=g\left(\mu_{i}\right)=\frac{1}{\mu_{i}} \quad \rightarrow \mu_{i}=g\left(\eta_{i}\right)^{-1}=\frac{1}{\eta_{i}}$ loglink : $\quad \eta_{i}=g\left(\mu_{i}\right)=\log _{e}\left(\mu_{i}\right) \rightarrow \mu_{i}=g\left(\eta_{i}\right)^{-1}=\mathrm{e}^{\eta_{i}}$

For clarity, the final parsimonious model for each response variable is presented in the results as the inverse link function form (i.e. $g\left(\eta_{i}\right)^{-1}$ ). All GLM formulae, coefficients and analytical output are presented in the supplementary materials.

Critical swimming speed $\left(\mathrm{U}_{\text {crit }}\right)$ was used as a potential explanatory variable in the GLMs to account for the varying levels of enforced swimming activity observed in different fish before the physiological samples were taken. Control group fish were assigned an arbitrarily low $\mathrm{U}_{\text {crit }}$ value (0.001), to represent the absence of enforced activity prior to sampling. In addition, five fish did not complete the first speed increment of the $U_{\text {crit }}$ procedure $\left(0.5 \mathrm{~m} \mathrm{~s}^{-1}\right)$ and were only fatigued to some degree and clearly not exhausted. Indeed, two fish stopped swimming only 2 min into the first speed increment and struggled vigorously after removal from the swim chamber. This complicated the calculation of $\mathrm{U}_{\text {crit }}$ as the fish had not completed a full speed increment. We chose to assign the fish the average water speed in the ramping from overnight to first speed increment as their fastest completed speed $\left(\mathrm{V}_{\mathrm{n}-1}\right)$ in the $\mathrm{U}_{\text {crit }}$ calculations, as this produces $\mathrm{U}_{\text {crit }}$ values that are more likely than using the overnight acclimation speed (see Section 2.3). The relationships between $U_{\text {crit }}$ and the other explanatory variables (see above) were also investigated using GLM (with a Gamma error distribution and an inverse link function).

\section{Results}

Critical swimming speed $\left(U_{\text {crit }}\right)$ of haddock $\left(0.66 \pm 0.18 \mathrm{~m} \mathrm{~s}^{-1}\right.$; $1.25 \pm 0.29 \mathrm{BL} \mathrm{s}^{-1}$; average $\pm \mathrm{SD}$ ) was positively correlated with body length ( $\mathrm{p}=0.015$, Fig. 3 ). In general, most fish swam for a considerable distance (typically greater than $1250 \mathrm{~m}$ ) and are likely to be exhausted.

Blood glucose was clearly affected by the swimming regime and remained elevated $(p<0.0001)$ throughout the entire recuperation period (Fig. 4). This was an effect of both recovery $(p<0.0001)$ and a positive correlation with HSI ( $\mathrm{p}=0.0064)$. The relationship with HSI is clearly apparent in the control group animals, but was more variable in the exhausted animals. Furthermore, the range of HSI was limited in some groups, particularly the 3-h recovery group.

The swimming regime also had a transient effect on the time to reach maximum muscle stiffness (Fig. 5), which was influenced mainly by recovery $(p<0.001)$ and a positive correlation with muscle $\mathrm{pH}_{\text {start }}$ $(p<0.05)$. Maximum muscle stiffness (Table 1$)$, on the other hand, was not affected by the recovery or muscle $\mathrm{pH}_{\text {start }}$ (see supplementary materials).

The relationship between blood lactate and its potential explanatory variables was complex. When modelled individually, the effect of swimming activity was expressed by the clear effect that recovery had on lactate concentrations $(p<0.0001)$, which were elevated in all exercised groups, but particularly the 6-h recovery group (Fig. 6). In addition, sex was also significant when modelled individually

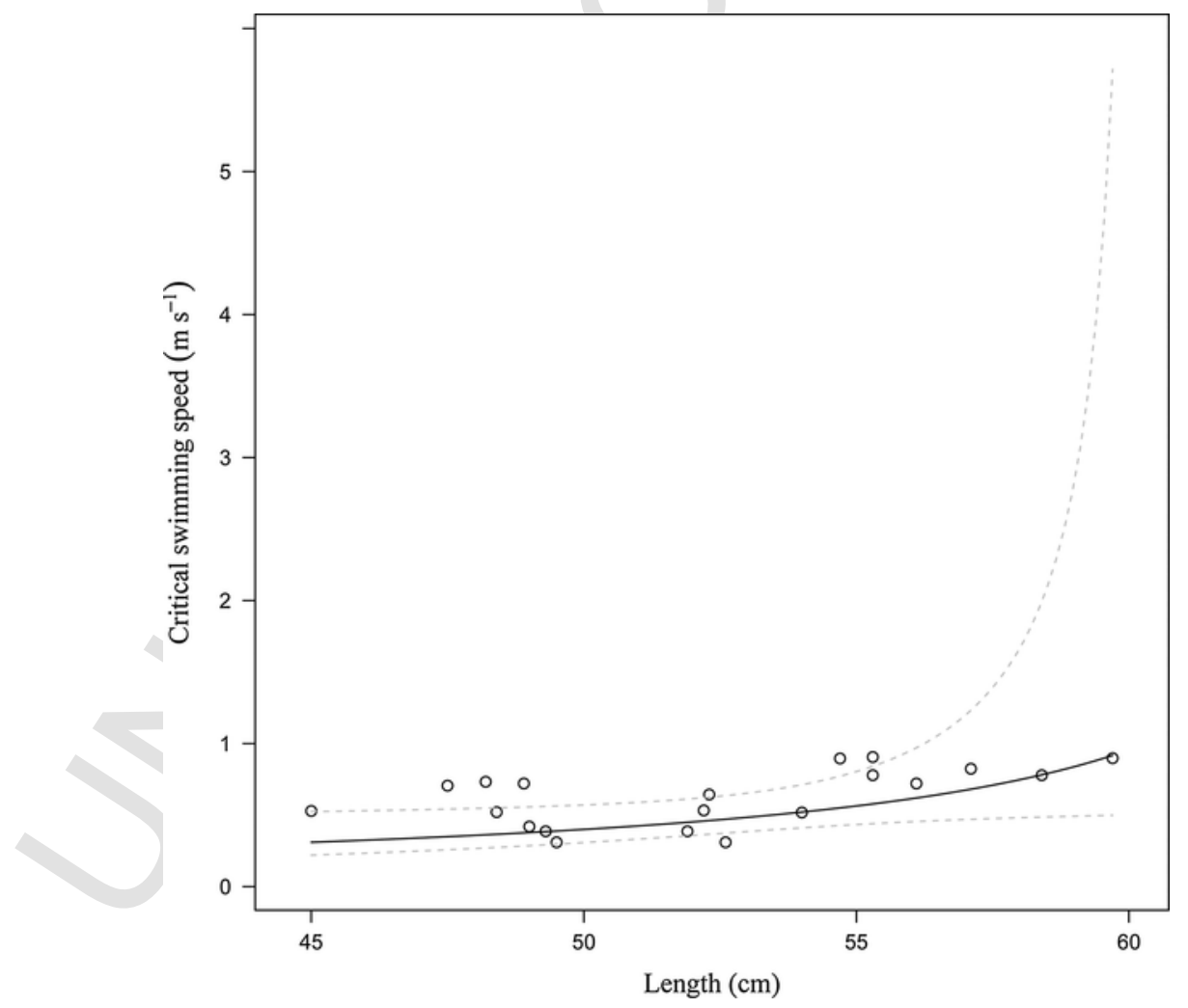

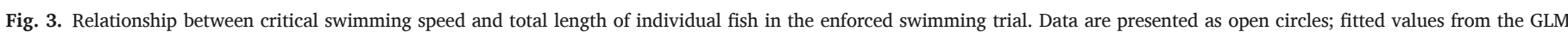
are shown as a solid black line and the corresponding $95 \%$ confidence interval as dashed grey lines. See supplementary materials for model details. 


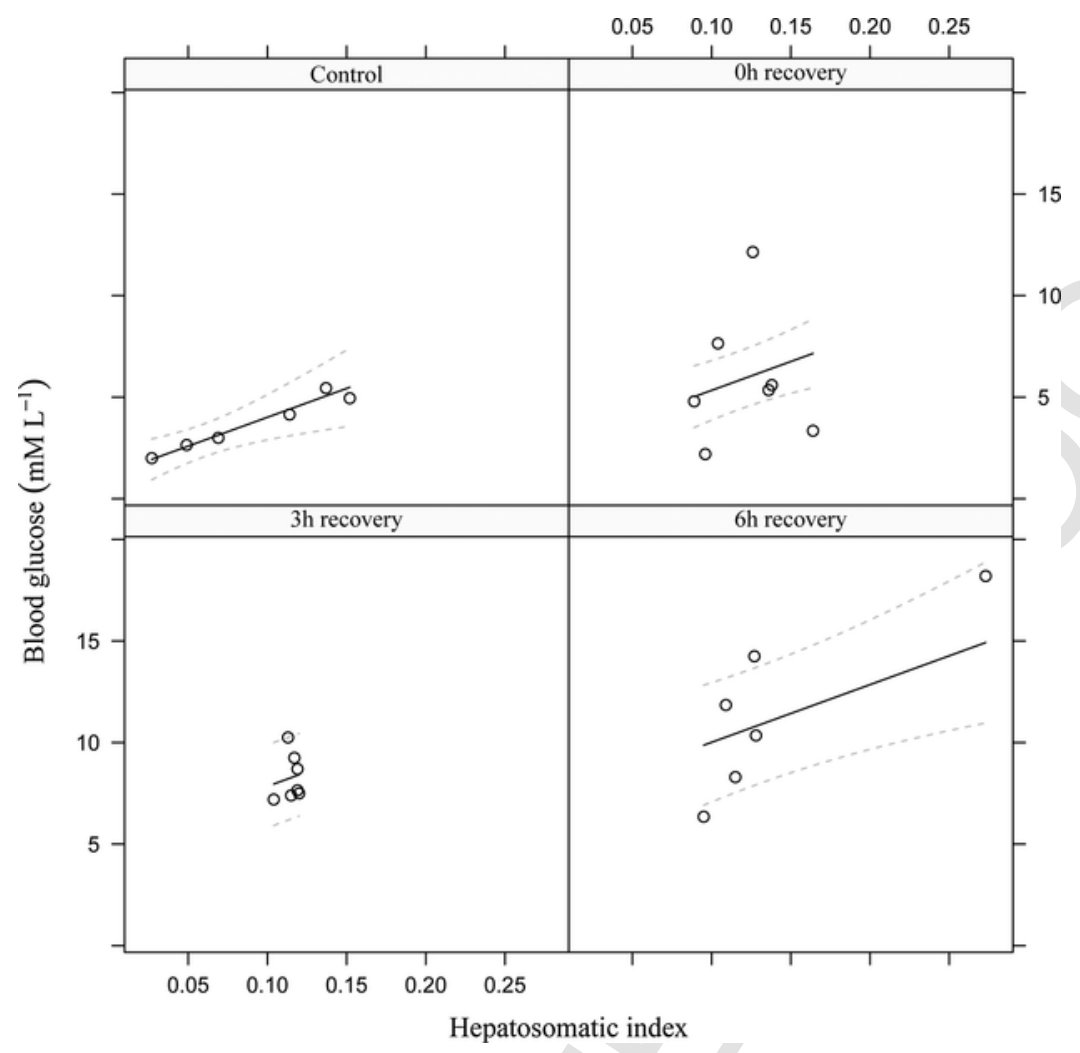

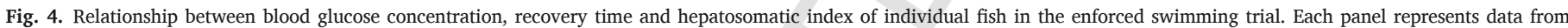

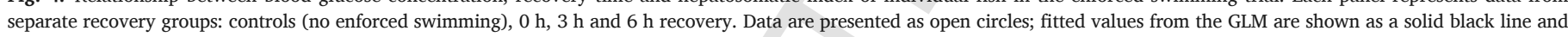
the corresponding $95 \%$ confidence interval as dashed grey lines. See supplementary materials for model details.

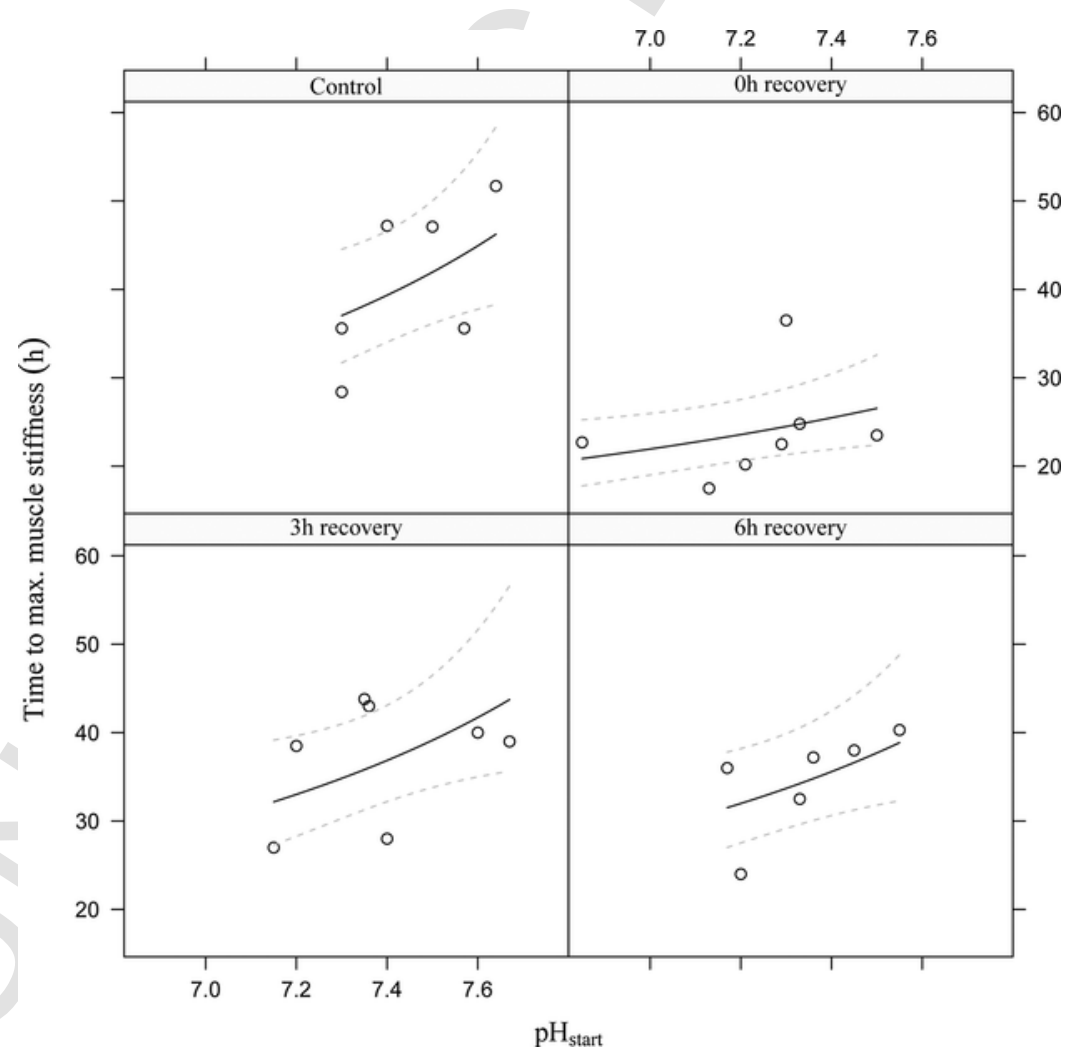

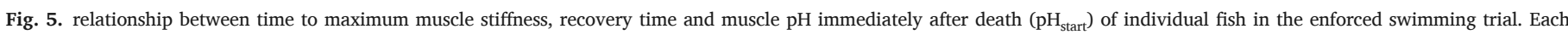

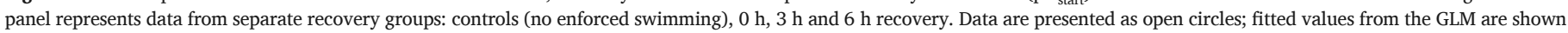
as a solid black line and the corresponding $95 \%$ confidence interval as dashed grey lines. See supplementary materials for model details. 


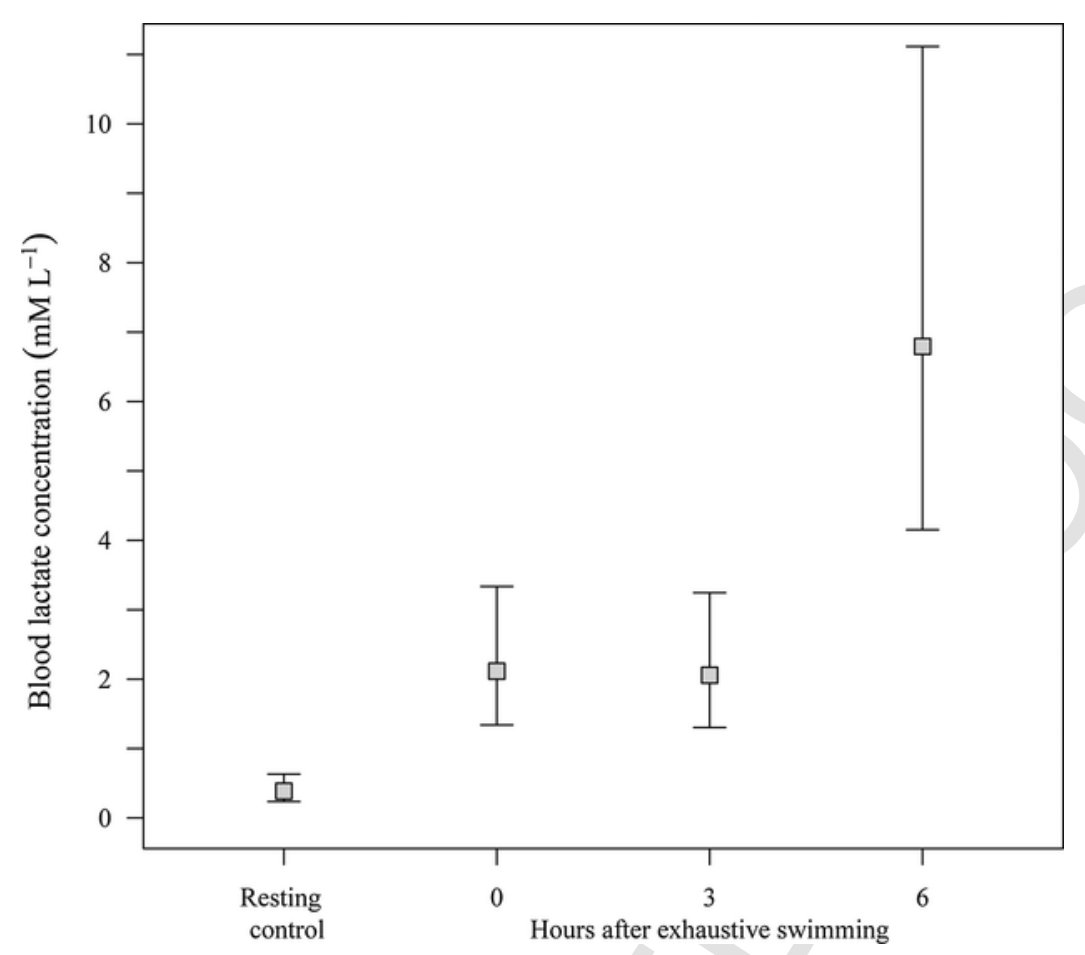

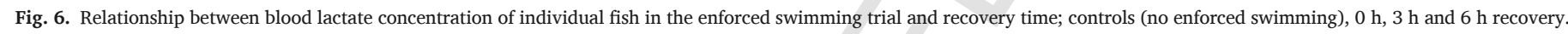
Fitted values from the GLM are shown as open squares and the corresponding 95\% confidence interval as "T" bars. See supplementary materials for model details.

( $p=0.0029)$, but this was highly dependent on just 3 females in the 6-h recovery group that had particularly high blood lactate concentrations. However, neither of these parameters were retained in the most parsimonious (final) model, selected from all relevant parameters.
In this final model, the importance of swimming activity on blood lactate was expressed by the highly significant positive correlation with $\mathrm{U}_{\text {crit }}(\mathrm{p}=0.0003)$ (Fig. 7). In addition, in the same model, blood lactate was also positively correlated with blood glucose $(p=0.0033)$

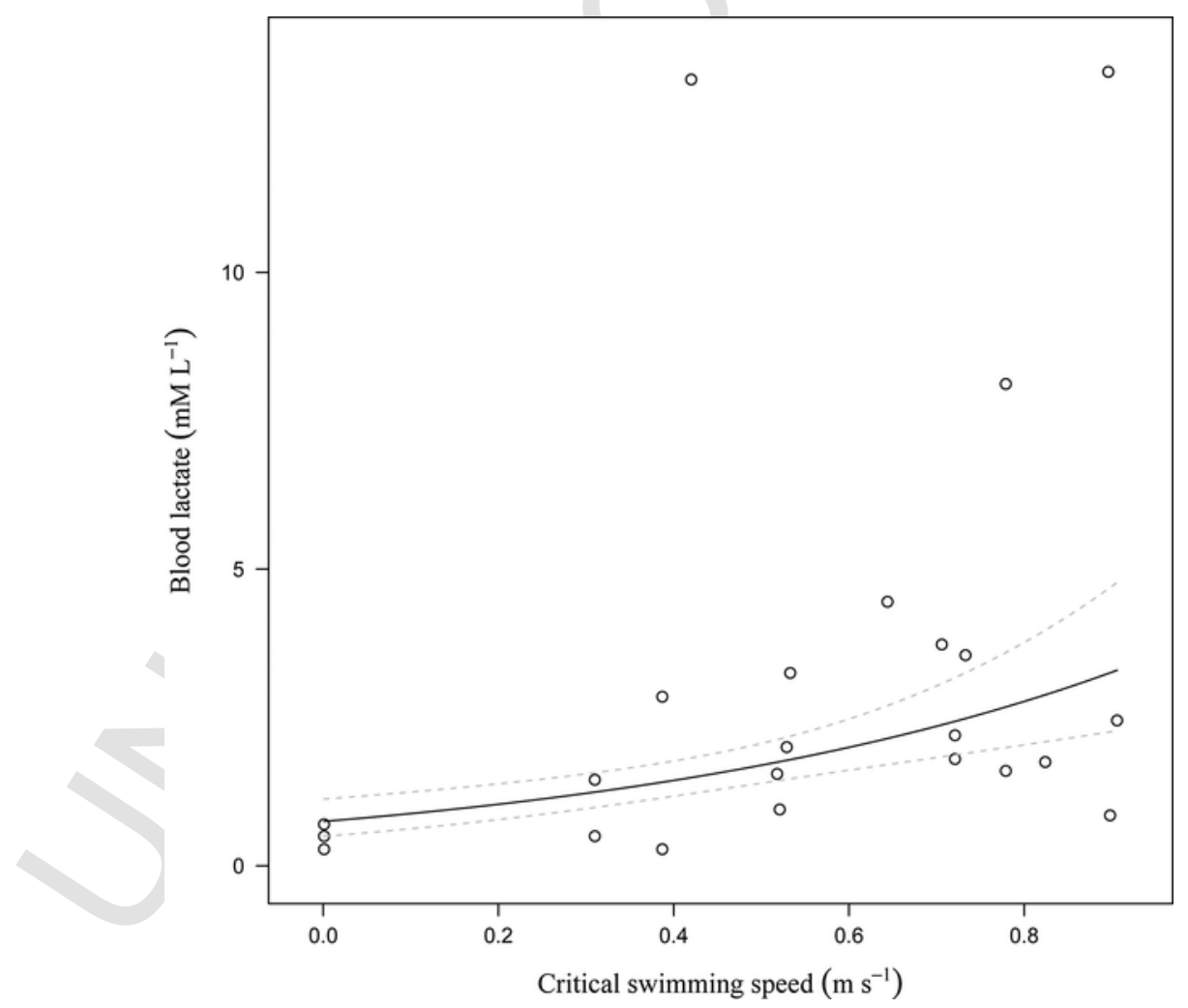

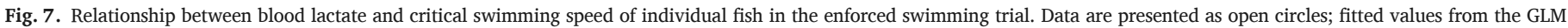
are shown as a solid black line and the corresponding $95 \%$ confidence interval as dashed grey lines. See supplementary materials for model details. 
and GSI $(\mathrm{p}=0.0025)$ and highly negatively correlated with $\mathrm{pH}_{\text {start }}$ $(p<0.0001)$.

Swimming activity had no apparent effect on muscle $\mathrm{pH}_{\text {start }}$ or $\mathrm{pH}_{\text {end }}$ (Table 1). The only significant explanatory variable for $\mathrm{pH}_{\text {start }}$ was blood lactate, which had a negative correlation $(\mathrm{p}=0.015)$, while

$\mathrm{pH}_{\text {end }}$ was positively correlated with HSI $(\mathrm{p}=0.0092)$, although the significance of this relationship was dependent on only two influential data points.

The whiteness of the fillet (Table 1) was also not affected by the swimming activity and only correlated positively with GSI $(p=0.0008)$ and negatively with HSI $(\mathrm{p}=0.0022)$. The relationship with HSI was highly dependent on just four influential data points, so its significance should be viewed with caution.

\section{Discussion}

\subsection{Swimming performance and level of exhaustion}

The average $\mathrm{U}_{\text {crit }}$ of haddock was $0.66 \pm 0.18 \mathrm{~m} \mathrm{~s}^{-1}$ or $1.25 \pm 0.29$ BL s ${ }^{-1}( \pm$ SD) and is the first account of aerobic swimming performance in haddock larger than $45 \mathrm{~cm}$ BL. Interestingly, this $\mathrm{U}_{\text {crit }}$ corresponds well with the maximum sustainable swimming speed $\left(\mathrm{U}_{\mathrm{ms}}\right)$ predicted by Breen et al. (2004) for the size of our fish $\left(0.63 \mathrm{~m} \mathrm{~s}^{-1}\right)$, although $U_{\text {crit }}$ and $\mathrm{U}_{\mathrm{ms}}$ are different measures of aerobic swimming performance. Maximum sustainable swimming speed $\left(\mathrm{U}_{\mathrm{ms}}\right)$ is a measure of the maximum speed at which a fish can maintain aerobic swimming activity, beyond which the fish will begin to utilise anaerobic swimming, start accumulating lactate in the white swimming muscles, and eventually become exhausted, if the swimming speed was maintained (Videler and Wardle, 1991). However, $U_{m s}$ is difficult to estimate because it requires multiple replicate swimming trials on the same fish over a wide range of swimming speeds (e.g. Breen et al., 2004). Conversely, $U_{\text {crit }}$ is a convenient method for obtaining a standardised and repeatable measure of swimming performance, although it has been criticised for its lack of ecological and eco-physiological relevance (Plaut, 2001). Furthermore, to date, no direct correlation between $\mathrm{U}_{\text {crit }}$ and $\mathrm{U}_{\mathrm{ms}}$ has been established, although some correlations with routine activity metrics and metabolism have been demonstrated (e.g. Brett and Glass, 1973; Plaut, 2000).

In this study, we observed a positive, linear relationship between $B L$ and $U_{\text {crit }}$, which is a well-established relationship observed in various species (e.g. Brett and Glass, 1973; Plaut, 2001; Videler, 1993). The critical swimming speed $\left(\mathrm{U}_{\text {crit }}\right)$ was based on data from individual fish swimming together in a group, while many previous studies on swimming performance in fish relied on swimming one individual at a time (Brett, 1964; Martinez et al., 2004; Sabate et al., 2013). Breen et al. (2004) also assessed swimming performance $\left(\mathrm{U}_{\text {crit }}\right)$ of fish in groups and demonstrated a substantial reduction in performance $(>50 \%)$ in most fish when they swam alone, compared to when swimming in a group. This difference was much greater than could be explained by any reduction in drag benefited by swimming in a school, and was thus attributed to the effect inter-conspecific competition on performance behaviour. Therefore, it is likely a combination of behavioural and physical factors (e.g. BL, temperature, fish condition) that determine the endurance of a fish swimming in the mouth of a trawl (Breen et al., 2004). Thus, the degree of exhaustion is likely to vary accordingly, including between individual fish.

\subsection{Recovery from exhaustion}

Blood glucose did not change significantly during swimming, but increased steadily during the entire 6-h period of recovery (Fig. 4). A similar pattern was observed for blood lactate (Fig. 6). Together, this indicates that physiological recovery after exhaustion takes more than
$6 \mathrm{~h}$ in haddock. This is in line with the findings of Beamish (1966), who observed a return to baseline blood lactate levels after $12 \mathrm{~h}$ post exhaustion. However, elevated blood glucose and lactate levels could also have been caused by stress following enforced swimming, as increased cortisol levels post-exercise can prolong lactate and glycogen recovery metabolism associated with increased hepatic glucose mobilization (Milligan, 1996; Mommsen et al., 1999). Although there was a significant effect of sex on blood lactate, these results should be treated with caution due to a low sample size in the sex divided groups $(n=2-4)$ and large individual variation. This is especially evident for the female 6-h recovery group median value, which had a wide $95 \%$ CI of 3.7-13.4 $\mathrm{mM} \mathrm{L}^{-1}$ (Fig. 6). The pattern observed in males represents a typical response to recovery after exhaustive swimming, although it is less pronounced than one could expect if all fish had been fully exhausted (Wood, 1991) or had been caught by trawl (Beamish, 1966; Olsen et al., 2013).

\subsection{Fillet quality and recovery from exhaustive swimming}

The haddock that were euthanized and sampled immediately after enforced swimming reached maximum muscle stiffness faster than the control and the 3- and 6-h recovery groups. Thus, there is a similar positive effect of recovery in our study, compared to that reported previously in both haddock (Digre et al., 2017) and Atlantic cod (Olsen et al., 2013) following trawling. Our results are also consistent with a recent study on Atlantic cod, which revealed only transient effects of exhaustive swimming on muscle stiffness (i.e. maximum muscle stiffness and time to reach maximum muscle stiffness) during recovery (Svalheim et al., 2017). A slowly increasing and/or low maximum muscle stiffness is beneficial in terms of fillet quality as it reduces the chance of muscle segment gaping (Borderías and Sánchez-Alonso, 2011). In general, pre-slaughter stress accelerates myofibre-myofibre detachment, which may cause muscle segment gaping. This in turn results in lower water content with a dryer and softer texture of the fillet, and also has a negative impact on the appearance of the fillet (Sigholt et al., 1997; Skjervold et al., 2001; Erikson and Misimi, 2008; Bahuaud et al., 2010; Borderías et al., 2011; Sánches-Alonzo, 2011). Although exhaustive swimming appeared to have some effects on fillet quality, the levels of most quality parameters examined here were similar to that reported by Svalheim et al. (2017) on exhaustive exercise in Atlantic cod and not as severe as observed for fish caught by trawl (Olsen et al., 2013; Digre et al., 2017). Muscle pH recorded immediately after exhaustion in our study was $7.23 \pm 0.08$, compared to $6.93 \pm 0.03$ and $7.01 \pm 0.11$, respectively, in haddock (Digre et al., 2017) and Atlantic cod (Olsen et al., 2013) caught by trawl. Also, there was no significant effect of exhaustive swimming on fillet colouration, as opposed to that reported for Atlantic cod caught by trawl (Olsen et al., 2013). However, enforced swimming is only one of several events during trawling that are potentially stressful and detrimental to fillet quality in fish (Svalheim et al., 2017). Therefore, it seems likely that other factors such as injury, barotrauma, crowding or asphyxiation in the codend, may contribute to the overall deterioration of fillet quality occasionally observed in haddock caught by trawl.

\subsection{Conclusions}

The observations of swimming performance in large haddock obtained in the present study is in accordance with previous data from smaller congeners, but appears to be dependent on body length. A complete recovery of blood lactate and glucose after swimming exhaustion likely requires more than $6 \mathrm{~h}$. All fillet quality parameters were unaffected by recovery time or had returned to control levels after $3 \mathrm{~h}$ of recovery, and were generally not severe. Thus, the poor fillet quality observed occasionally in haddock caught by trawl is probably not caused 
by exhaustive swimming alone, but is more likely the result of several factors operating during the trawling process. Further research into these factors is needed to identify the poor-quality culprit in trawled haddock and other gadoids.

\section{Uncited reference}

Olsen et al. (2008).

\section{Acknowledgements}

This study was funded by the Norwegian Research Council through the Centre for Research-based Innovation in Sustainable fish capture and Processing technology (CRISP, project no. 21161). The capture and transport of live haddock to Troms $\varnothing$ aquaculture research station was funded by The Norwegian Seafood Research Fund (FHF, Project No: 900806). The authors would therefore like to thank the crew of Korsnesfisk for their extraordinary efforts to deliver live haddock to this project. The valuable help from the technical staff at the University of Troms $\varnothing$, Troms $\varnothing$ aquaculture research station and Nofima AS is also gratefully acknowledged. Permission to carry out this experiment was granted by the Norwegian Animal Welfare Authority (ID 5123).

\section{Appendix A. Supplementary data}

Supplementary data associated with this article can be found, in the online version, at http://dx.doi.org/10.1016/j.fishres.2017.09.006.

\section{References}

Akaike, H., 1974. A new look at the statistical model identification. IEEE Trans. Autom. Control 19 (6), 716-723. https://doi.org/10.1109/TAC.1974.1100705.

Bahuaud, D., Mørkøre, T., Østbye, T.K., Veiseth-Kent, E., Thomassen, M.S., Ofstad, R. 2010. Muscle structure responses and lysosomal cathepsins B and L in farmed Atlantic salmon (Salmo salar L.) pre- and post-rigor fillets exposed to short and long-term crowding stress. Food Chem. 118, 602-615.

Beamish, F.W.H., 1966. Muscular fatigue and mortality in haddock Melanogrammus aeglefinus caught by otter trawl. J. Fish. Res. Board Can. 23 (10), 1507-1521. https:// doi.org/10.1139/f66-141.

Beamish, F.W.H., 1968. Glycogen and lactic acid concentrations in atlantic cod (Gadus morhua) in relation to exercise. J. Fish. Res. Board Can. 25 (5), 837-851.

Berg, T., Erikson, U., Nordtvedt, T., 1997. Rigor mortis assessment of Atlantic salmon (Salmo salar) and effects of stress. J. Food Sci. 62 (3), 439-446.

Borderías, A.J., Sánchez-Alonso, I., 2011. First processing steps and the quality of wild and farmed fish. J. Food Sci. 76 (1), R1-R5. https://doi.org/10.1111/j.1750-3841.2010. 01900.x.

Breen, M., Dyson, J., O'Neill, F.G., Jones, E., Haigh, M., 2004. Swimming endurance of haddock (Melanogrammus aeglefinus L.) at prolonged and sustained swimming speeds, and its role in their capture by towed fishing gears. ICES J. Mar. Sci. 61, 1071-1079.

Brett, J.R., Glass, N.R., 1973. Metabolic rates and critical swimming speeds of sockeye salmon (Oncorhynchus nerka) in relation to size and temperature. J. Fish. Res. Board Can. 30, 379-387.

Brett, J.R., 1964. The respiratory metabolism and swimming performance of young sockeye salmon. J. Fish. Res. Board Can. 21 (5), 1183-1226.

Buckley, Y.M., 2015. Generalized linear models. In: Fox, G.A., Negrete-Yankelevich, S., Sosa, V.J. (Eds.), Ecological Statistics: Contemporary Theory and Application. Oxford University Press.

Burnham, K.P., Anderson, D.R., 2004. Multimodel inference: understanding AIC and BIC in model selection. Sociolo. Methods Res. 33, 261-304. https://doi.org/10.1177/ 0049124104268644

Cole, R.G., Alcock, N.K., Handley, S.J., Grange, K.R., Black, S., Cairney, D., Day, J., Ford, S., Jerret, A.R., 2003. Selective capture of blue cod Parapercis colias by potting: behavioural observations and effects of capture method on peri-mortem fatigue. Fish. Res. 60, 381-392.

Digre, H., Rosten, C., Erikson, U., Mathiassen, J.R., Aursand, I.G., 2017. The on-board live storage of Atlantic cod (Gadus morhua) and haddock (Melanogrammus aeglefinus) caught by trawl Fish behaviour, stress and fillet quality. Fish. Res. 189, 42-54.

Erikson, U., Misimi, E., 2008. Atlantic salmon skin and fillet color changes effected by perimortem handling stress, rigor mortis, and ice storage. J .Food Sci 73, C50-C59, (Lenth, R.V., 2015. lsmeans: Least-squares means, R package version 2.17.) http:// CRAN.R-project.org $/$ package $=$ lsmeans.
Lurman, G.J., Bock, C.H., Portner, H.O., 2007. An examination of the metabolic processes underpinning critical swimming in Atlantic cod (Gadus morhua L.) using in vivo P-31-NMR spectroscopy. J. Exp. Biol. 210 (21), 3749-3756.

Main, J., Sangster, G.I., 1981. A study on the fish capture process in a bottom trawl by direct observations from a towed underwater vehicle. Scott. Fish. Res. Rep. 23, 1-24.

Margeirsson, S., Jonsson, G.R., Arason, S., Thorkelsson, G., 2007. Influencing factors on yield, gaping, bruises and nematodes in cod (Gadus morhua) fillets. J. Food Eng. 80 (2), 503-508. https://doi.org/10.1016/j.jfoodeng.2006.05.032.

Martinez, M., Bedard, M., Dutil, J.D., Guderley, H., 2004. Does condition of Atlantic cod (Gadus morhua) have a greater impact upon swimming performance at U-crit or sprint speeds?. J. Exp. Biol. 207 (17), 2979-2990.

McCullagh, P., Nelder, J., 1999. Generalized Linear Models, second edition Chapman and Hall/CRC, London.

Michie, I., 2001. Causes of downgrading in the salmon industry. In: Kestin, S.C., Warriss, P.D. (Eds.), Farmed Fish Quality. Blackwell, Oxford, UK, pp. 405-406.

Milligan, C.L., 1996. Metabolic recovery from exhaustive exercise in rainbow trout. Comp. Biochem. Physiol. A 113 (1), 51-60.

Mommsen, T.P., Vijayan, M.M., Moon, T.W., 1999. Cortisol in teleosts: dynamics, mechanisms of action, and metabolic regulation. Rev. Fish. Biol. Fish. 9 (3), 211-268.

Neumann, P., Holeton, G.F., Heisler, N., 1983. Cardiac output and regional blood flow in gills and muscles after exhaustive exercise in rainbow trout (Salmo gairdneri). J. Exp Biol. 105, 1-14.

Norwegian fish landing statistics, 2014. Norwegian Directorate of Fisheries, Accessed 27.11.2014 http://www.fiskeridir.no/fiskeridirektoratets-statistikkbank.

Olsen, S.H., Sorensen, N.K., Stormo, S.K., Elvevoll, E.O., 2006. Effect of slaughter methods on blood spotting and residual blood in fillets of Atlantic salmon (Salmo salar). Aquaculture 258, 462-469.

Olsen, S.H., Sorensen, N.K., Larsen, R., Elvevoll, E.O., Nilsen, H., 2008. Impact of pre-slaughter stress on residual blood in fillet portions of farmed Atlantic cod (Gadus morhua) - Measured chemically and by Visible and Near-infrared spectroscopy. Aquaculture 284, 90-97.

Olsen, S.H., Tobiassen, T., Akse, L., Evensen, T.H., Midling, K.O., 2013. Capture induced stress and live storage of Atlantic cod (Gadus morhua) caught by trawl: consequences for the flesh quality. Fish. Res. 147, 446-453.

Olsson, G.B., Seppola, M.A., Olsen, R.L., 2007. Water-holding capacity of wild and farmed cod (Gadus morhua) and haddock (Melanogrammus aeglefinus) muscle during ice storage. LWT Food Sci. Tech. 40 (5), 793-799. https://doi.org/10.1016/j.lwt.2006. 04.004.

Plaut, I., 2000. Resting metabolic rate, critical swimming speed and routine activity of the euryhaline cyprinodontid, Aphanius dispar, acclimated to a wide range of salinities. Physiol. Biochem. Zool. 73, 590-596.

Plaut, I., 2001. Critical swimming speed: its ecological relevance. Comp. Biochem. Physiol. A $131,41-50$.

R core team, 2015. R: A Language and Environment for Statistical Computing, Version 3.2.0. R Foundation for Statistical Computing, Vienna, Austria http://www.R-project. org/.

Reidy, S.P., Kerr, S.R., Nelson, J.A., 2000. Aerobic and anaerobic swimming performance of individual Atlantic cod. J. Exp. Biol. 203, 347-357.

Robb, D., Whittington, P., 2004. Fish Welfare: a Quality Issue. Fish Farming International, 28, (January).

Robb, D.H.F., Phillips, A.J., Kestin, S.C., 2003. Evaluation of methods for determining the prevalence of blood spots in smoked Atlantic salmon and the effect of exsanguination method on prevalence of blood spots. Aquaculture 217, 125-138.

Roth, B., Rotabakk, B.T., 2012. Stress associated with commercial longlining and recreational fishing of saithe (Pollachius virens) and the subsequent effect on blood gases and chemistry. Fish. Res. 115, 110-114.

Roth, B., Torrissen, O.J., Slinde, E., 2005. The effect of slaughtering procedures on blood spotting in rainbow trout (Oncorhynchus mykiss) and Atlantic salmon (Salmo salar). Aquaculture 250, 796-803.

Roth, B., Obach, A., Hunter, D., Nortvedt, R., Oyarzun, F., 2009. Factors affecting residual blood and subsequent effect on bloodspotting in smoked Atlantic salmon fillets. Aquaculture 297, 163-168.

Sabate, F.D., Nakagawa, Y., Nasu, T., Sakamoto, W., Miyashita, S., 2013. Critical swimming speed and maximum sustainable swimming speed of juvenile Pacific bluefin tuna, Thunnus orientalis. Aquacult. Int. 21 (1), 177-181.

Sigholt, T., Erikson, U., Rustad, T., Johansen, S., Nordtvedt, T.S., Seland, A., 1997. Handling stress and storage temperature affect meat quality of farmed-raised Atlantic salmon (Salmo salar). J. Food Sci. 62, 898-905.

Skjervold, P.O., Fjaera, S.O., Ostby, P.B., 1999. Rigor in Atlantic salmon as affected by crowding stress prior to chilling before slaughter. Aquaculture 175, 93-101.

Skjervold, P.O., Fjæra, S.O., Østby, P.B., Einen, O., 2001. Live-chilling and crowding stress before slaughter of Atlantic salmon (Salmo salar). Aquaculture 192, 265-280.

Sogn-Grundvåg, G., Larsen, T.A., Young, J.A., 2013. The value of line-caught and other attributes: an exploration of price premiums for chilled fish in UK supermarkets. Mar. Policy 38, 41-44.

Svalheim, R.A., Karlsson-Drangsholt, A., Olsen, S.H., Johnsen, H.K., Aas-Hansen, , 2017. Effects of exhaustive swimming and subsequent recuperation on flesh quality in unstressed Atlantic cod (Gadus Morhua). Fish. Res. 193, 158-163.

Videler, J.J., Wardle, C.S., 1991. Fish swimming stride by stride: speed limits and endurance. Rev. Fish Biol. Fish. 1, 23-40.

Videler, J.J., 1993. Fish Swimming. Chapman and Hall, London, (260 pp).

Wood, C.M., 1991. Acid-base and ion balance, metabolism, and their interactions, after exhaustive exercise in fish. J. Exp. Biol. 160, 285-308. 
Zuur, A., Ieno, E.N., Elphick, C., 2009. A protocol for data exploration to avoid common statistical problems. Methods Ecol. Evol. https://doi.org/10.1111/j.2041-210x.2009. 00001.x. 